\title{
A RESPONSABILIDADE ENQUANTO FUNDAMENTO ÉTICO PARA PENSAR A EDUCAÇÃO: APORTES JONASIANOS
}

\author{
Cláudia Battestin ${ }^{1}$ \\ Gomercindo Ghiggi ${ }^{2}$ \\ Robinson dos Santos ${ }^{3}$
}

\section{Resumo}

O presente artigo é resultante de uma pesquisa bibliográfica que busca resgatar a importância da delimitação do conceito de responsabilidade, que através do pensamento jonasiano, passa a ampliar a dimensão para o campo da ética. Neste impasse, passou-se a analisar além do novo imperativo, a dimensão e o alcance da Responsabilidade, que além de ser a primeira obrigação da reflexão ética, passa a assumir um importante papel na Educação.

Palavras-chave: Educação. Filosofia. Responsabilidade. Ética. Hans Jonas.

\section{Resumen}

El presente artículo resulta de una investigación bibliográfica que busca rescatar la importancia de la delimitación del concepto de responsabilidad, que a través del pensamiento jonasiano pasa a ampliar la dimensión al campo de la ética. En este impase, se pasó a analizar hacia más allá del nuevo imperativo, la dimensión y el alcance de la Responsabilidad, que además de ser la primera obligación de la reflexión ética, pasa a asumir un importante papel en la Educación.

Palabras clave: Educación. Filosofía. Responsabilidad. Ética. Hans Jonas.

\section{A importância e delimitação da Responsabilidade}

Neste primeiro momento do texto, considera-se extremamente válido, mesmo que de forma breve, uma investigação sobre o que vem a ser Responsabilidade, pois a delimitação histórica e conceitual do tema contribui de forma significativa para compreensão do que vem a ser a proposta Jonasiana.

\footnotetext{
${ }^{1}$ Doutora em Educação pela Universidade Federal de Pelotas (UFPel). Professora do departamento de Ciências Humanas da Universidade Regional Integrada do Alto Uruguai e das Missões (URI) Campus Frederico Westphalen.Email:battestin@uri.edu.br

${ }^{2}$ Doutor em Educação pela Universidade Federal do Rio Grande do Sul (UFRGS).Professor do Programa de Pós Graduação em Educação da Universidade Federal de Pelotas (UFPel).

${ }^{3}$ Doutor em Filosofia pela Universidade de Kassel (Alemanha).Professor do Departamento de Filosofia e do Programa de Pós-graduação em Filosofia da Universidade Federal de Pelotas (UFPel).
}

BATTESTIN, Cláudia; GHIGGI, Gomercindo; SANTOS, Robinson dos. A responsabilidade enquanto fundamento ético para pensar a educação: aportes jonasianos. Revista Sul-Americana de Filosofia e Educação. Número 25: nov/2015abr/2016, p. 4-19. 
Concomitantemente, a palavra responsabilidade (respondere) é de origem latina, ou seja, não é um termo antigo, comparado com outras palavras que tiveram origem na Grécia Antiga. Segundo Abbagnano (2007), o termo apareceu pela primeira vez em inglês (responsibility) e em francês (responsabilité), no ano de 1787, e é somente depois deste período que a palavra chega à língua portuguesa.

$\mathrm{O}$ conceito de responsabilidade se modifica e se transforma na modernidade. Para muitos pensadores, como Ricoeur (1990), a "noção" de responsabilidade é tão antiga quanto um conhecimento do mundo moral, mas com uma diversidade de sentidos e interferência das perspectivas do campo jurídico, sociológico e religioso. Outrora, o autor apresenta o conceito de responsabilidade com a noção do dever, de obrigação, um conceito formal e jurídico, confundindo a liberdade do individuo com a liberdade do cidadão que estaria sujeito às leis ${ }^{4}$. Segundo Ricouer, o emprego do termo responsabilidade causa perplexidade, apontando diferentes divergências no campo jurídico, por exemplo: "Por um lado, o conceito parece ainda bem fixado em seu uso jurídico clássico (...) ao mesmo tempo, a vagueza invade a cena conceitual (...) sem inscrição marcada na tradição filosófica" (2008, p.33). Quando a "vagueza" invade a "cena conceitual" da responsabilidade, o termo usual é a imputação, empregado nas relações referidas ao ato de responder e nas obrigações cabíveis. Porém, complementa Ricouer, "o termo imputação é bem conhecido numa época em que o termo responsabilidade não tem emprego reconhecido fora da teoria política (...)" (2008, p.35-36).

É por essa via que o autor salienta a importância de delimitar o conceito de imputação, pois, "Imputar, dizem nossos melhores dicionários, é atribuir a alguém uma ação condenável, um delito, portanto uma ação confrontada previamente com uma obrigação ou uma proibição que essa ação infringe" (2008, p.36).

Hodiernamente, precisamos reconhecer a necessidade de fundamentar a responsabilidade no sentido moral, pois ela é essencialmente importante para as exigências e escolhas de nossa contemporaneidade. Segundo Etchegoyen (1999,

\footnotetext{
${ }^{4}$ Porém, na linguagem jurídica, ou em outras decorrentes, a tendência é perguntar sempre pelo responsável de um ato cometido quando o problema for ocasionado por um dano. Entretanto, pergunta-se pelo responsável quando a ação é positiva? $\mathrm{O}$ uso do termo responsabilidade, infelizmente, vem sendo usado de forma redutível e descontextualizada.
} 
p.61), a responsabilidade moral não pode e não deve ser imposta por uma lei, já que ela é o resultado de um enquadramento e de uma vontade consciente, sendo o enquadramento prospectivo. Ao contrário, na responsabilidade jurídica, na qual os deveres são determinados pela lei, procura-se uma causa que originou o dano, $e$ os procedimentos são retroativos. Poderia então o homem responsável responder e agir segundo o que julgar ser correto? A resposta sempre será determinante e essencial ao conceito da responsabilidade, pois remeterá a uma noção de causalidade. A responsabilidade moral não depende exclusivamente do conhecimento, mas sim da relação que se tem com o outro.

Por outro viés, Jean Louis Gernard, autor do ensaio linguístico $A$ Gramática da Responsabilidade (La Grammaire de La Responsabilité), faz um delineamento diante de dois aspectos: o primeiro está ligado a uma afirmação correlacionada à autonomia subjetiva, que acentua a subjetividade (subjectivitê) da responsabilidade centrada no eu (je), ou seja, no individualismo (individualité). O segundo aspecto analisado pelo autor é a ampliação da responsabilidade pelo outro (autre), pelo próximo, podendo, desta forma, ampliar a responsabilidade para o âmbito coletivo. Segundo Gernard, para compreende a responsabilidade é preciso saber como ela se articula com as afirmações: do $e u$, do cuidado com o outro e a do eu perante o outro. Entretanto, como seria possível compreender esses modelos com aparências tão contraditórias? $\mathrm{O}$ autor compreende que: "Todas as culturas têm procurado responder a esta pergunta e, de fato, trouxeram uma variedade de respostas, por meio das quais estruturam suas relações com o mundo" (1999, p.75). De imediato, poder-se-ia pensar: Qual responsabilidade deveria ser assumida diante da relação com o mundo? A Responsabilidade no sentido moral seria a mais apropriada para as emergências contemporâneas uma vez que a mesma, segundo Etchegoyen (1999, p.61), não é imposta por uma lei, pois resulta da consciência de cada sujeito e da sua relação com o outro.

Ao encontro dessa ideia, compreendemos que a Responsabilidade moral deve e pode ser apresentada enquanto obrigação moral, e não simplesmente pela via de uma lei que poderá reparar o mal causado a outro. Aquela expressão que se ouve: o "sentimento de responsabilidade" aplica-se justamente na 
Responsabilidade moral, definida também como capacidade e obrigação que se tem em assumir os seus atos. Na mesma dimensão de entendimento, Brüseke (2002, p.25) apresenta a possibilidade do homem poder assumir a responsabilidade através das próprias ações, assim ele poderá confrontar-se com a responsabilidade de um possível fracasso. Essa consciência do risco poderá ser entendida como uma nova situação social determinante.

Todavia, a Responsabilidade moral só será compreendida como um princípio, uma obrigação não recíproca, na medida em que as questões éticas forem se deslocando para a condição da vulnerabilidade da vida, ou seja, uma Responsabilidade ética que, no olhar de Jonas, deve abarcar toda a biosfera.

\section{A Responsabilidade em Hans Jonas: aportes e convergências}

Na compreensão jonasiana, a Responsabilidade (verantwortung) é um princípio (prinzip) que não pode estar externo ao indivíduo, uma vez que não se pode mandar uma pessoa agir com sentimento ou responsabilidade em nome de outra. No entanto, afirma Jonas, “(...) aquilo que não existe, não faz reivindicações, e nem por isso pode ter seus direitos lesados. Que os tenha quando existir, mas não os tenha por conta da possibilidade de que existirá algum dia" (2006, p.89). O respeito e a responsabilidade pela humanidade devem estar permanentemente em consonância com o futuro, e Jonas tem clara essa ideia ao afirmar que: "Zelar por isso, tal é nosso dever básico para com o futuro da humanidade, a partir do qual podemos deduzir todos os demais deveres para com os homens futuros" (2006, p.93). O dever (pflicht) não precisa estar relacionado ao sujeito da ação moral, e nem a ação moral em si, no dever. O que deve estar relacionado é o bem em si no mundo; este deverá manter-se diante da vontade individual, tanto que Jonas afirma:

Para que algo me atinja $e$ me afete de maneira a influenciar minha vontade é preciso que eu seja capaz de ser influenciado por esse algo. Nosso lado emocional tem de entrar em jogo. E é da própria essência da nossa natureza moral que a nossa intelecção nos transmita um apelo que 
encontre uma resposta em nosso sentimento. É o sentimento de responsabilidade (2006, p.156-157).

A teoria da Responsabilidade, assim como qualquer outra teoria ética, deve ou deveria estar ancorada em pilares que sustentam, além da razão, sentimentos e emoções. É por essa via que Jonas compreende que “(...) a ética tem um aspecto objetivo e outro subjetivo, aquele tratando da razão e este, da emoção" (2006, p.157). Historicamente, o aspecto objetivo sempre chamou mais a atenção dos filósofos. Porém, tanto o aspecto objetivo como o subjetivo são complementares e fundamentais para a ética, pois a lacuna existente entre a "(...) sanção abstrata e a motivação concreta", afirma Jonas, "só pode ser transposta pelo arco do sentimento, o único capaz de influenciar a vontade" (2006, p.158). No entanto, Jonas reconhece que o "arco do sentimento" (arc gefühl) foi reconhecido pelos filósofos da moral, porque os mesmos perceberam que a razão deveria unir-se ao sentimento, ou seja, “(...) a moral que supomos que deve se impor às emoções necessita, ela própria, de emoções" (2006, p.159). Um exemplo que determina o "elemento emocional" pode ser visualizado por diversas teorias apresentadas no decorrer da história, tanto que o próprio Jonas exemplifica: "O 'temor de Deus' judaico, o 'eros' platônico, a 'eudemonia' aristotélica, o 'amor' cristão, o 'amor dei intellectualis' de Spinoza, (...) são formas de determinação desse elemento emocional da ética" (2006, p.159). O sentimento ou "elemento emocional da ética" (emotionale Element der Ethik) serve para justificar o quanto a ação moral é movida por um significado ontológico; ou seja, o sentimento que Jonas propõe é vulnerável (verwundbar), sem a pretensão de apropriação, caso contrário, não seria possível haver um sentimento de responsabilidade. Complementando a ideia de Duplá "Razão e sentimento, objetividade e responsabilidade são a juízo de Jonas dois aspectos indissolúveis da vida moral (1997, p.137).

Por outro lado, Hans Jonas rompe com a ideia de responsabilidade, entendida exclusivamente como imputabilidade (zurechenbarkeit), e anuncia uma Responsabilidade baseada na profundidade do ser vulnerável, que, além de pensar 
no futuro e na continuidade da vida, clama pela prudência, pelo respeito e pela dignidade ${ }^{5}$ diante de toda e qualquer fragilidade natural da vida, ou seja, a essência da própria Natureza. Conforme destaca Kuiava, com Jonas a responsabilidade:

(...) não é mais centrada no passado e no presente. A sua preocupação é com o futuro da humanidade, com as gerações futuras e com a sobrevivência das mesmas. Diferente de Platão, Jonas não está preocupado com a eternidade, mas com o tempo vindouro, compatível com a era da ciência e da tecnologia, cuja responsabilidade passa a ser o alicerce, o princípio orientador para as decisões que possam interferir nas diferentes formas de vida (2006, p.01).

Embora tenha sido reconhecido que a responsabilidade já foi aplicada aos assuntos da "cidade" e dos "homens", é preciso reconhecer que ela nunca esteve presente nas prioridades, nem nas exigências dos assuntos da Natureza. Por fim, apostar na Responsabilidade implica acreditar em um princípio no qual as obrigações não sejam recíprocas, e Kuiava (2006, p.01) fortalece esse pensamento ao afirmar que com Jonas a Responsabilidade não é mais centrada no passado e/ou no presente. Agora, a sua preocupação é com o futuro, com as gerações futuras e com a sobrevivência das mesmas.

\section{Por que a necessidade de uma ética fundamentada na Responsabilidade?}

Primeiramente, para compreender o porquê da necessidade $e$ da importância de uma ética fundamentada na Responsabilidade, é preciso observar o quanto a relação do Homem com a Natureza foi alterada através dos tempos: motivo que levou Jonas a analisar a validade dos antigos preceitos éticos por meio de cinco vias:

Primeira via: "Todo o trato com o mundo extra-humano, isto é, todo o domínio da techne (habilidade) era - à exceção da medicina - eticamente neutro" (2006, p.35). Ou seja, a ação humana não visava ao cuidado ${ }^{6}$ com o mundo extra-

\footnotetext{
${ }^{5}$ Jonas mostra a dignidade como sendo a dignidade da vida, a qual é maior do que o humano. Seu fundamento está além de todo o julgamento ético e de qualquer ação que se deseja realizar (MEISTER, 2008, p.10).

${ }^{6} \mathrm{O}$ cuidado é uma atitude que comporta atenção e dedicação ao outro. É dando atenção ao outro, ao próximo, que nasce o compromisso da solidariedade.
} 
humano, e a ética não se ocupava da técnica, uma vez que "(...) a atuação sobre objetos não humanos não formava um domínio eticamente significativo" (2006, p.35).

Segunda via: O significado da ética tradicional, de acordo com Jonas, diz respeito "(...) ao relacionamento direto de homem com homem, inclusive o de cada homem consigo mesmo; toda ética tradicional é antropocêntrica" (2006, p.35). Ou seja, o antropocentrismo (anthropozentrismus) faz parte da ética tradicional, pois o individualismo predominou constantemente na vida dos seres humanos, não abrindo espaço para a coletividade (kollektivität).

Terceira via: Contudo, afirma Jonas: "Para efeito da ação nessa esfera, a entidade 'homem' e sua condição fundamental era considerada como constante quanto à sua essência, não sendo ela própria objeto da techne (arte) reconfiguradora" (2006, p. 35). Nessa perspectiva, o homem não fazia parte da finalidade da técnica, porém, através de sua essência (essenz), era possível estabelecer e fundamentar o que era bom para a ética.

Quarta via: Jonas compreende que: "O bem e o mal, com o qual o agir tinha de se preocupar, evidenciavam-se na ação, seja na própria práxis, seja em seu imediato e não requeriam um planejamento de longo prazo" (2006, p.35). Definitivamente, as consequências das ações humanas não eram visadas no futuro, uma vez que a ética tradicional tinha como alcance "o aqui e o agora," visando situações recorrentes e típicas da vida privada e pública.

Quinta via: Por fim, Jonas chega à conclusão de que: “(...) os mandamentos $e$ as máximas da ética tradicional, fossem quais fossem suas diferenças de conteúdo, demonstram esse confinamento ao círculo imediato da ação" (2006, p.36). Ou seja, as máximas conhecidas pela ética ou pela religião estavam voltadas para ações imediatas, de maneira próxima e recíproca, sem um olhar atento para o dia de amanhã. O próprio Jonas cita alguns exemplos: "Ama teu próximo como a ti mesmo"; "Faze aos outros o que gostaria que eles fizessem a ti"; "Instrui teu filho no caminho da verdade"; "Almeja a excelência por meio do desenvolvimento e da realização das melhores possibilidades da tua existência como homem";Submete o teu bem pessoal ao bem comum"; "Nunca trate os teus 
semelhantes como simples meios, mas sempre como fins em si mesmo" (2006, p. 36).

Lembrando que se as máximas das éticas tradicionais diziam, por exemplo, "é preciso ser prudente", é necessário levar em consideração que essa prudência era aplicada ou exercida apenas entre os muros das cidades. Essa ideia, segundo Jonas, mudou em consequência da magnitude e do alcance da Técnica Moderna:

Que precisamente esta civilização ameaça o seu criador com sua "superioridade", é dizer, por exemplo, a crescente automatização (um triunfo da eletrônica) o desloca de seus postos de trabalho aos que outrora demonstravam sua condição humana. E com a ameaça de que sua sobre-exploração da natureza terrestre possa alcançar um ponto de catástrofe (1997, p.30).

É nesta perspectiva que Jonas analisa a inviabilidade das éticas tradicionais para garantir a vida em um espaço onde a ciência e a tecnologia exercitam o seu poder, lembrando que, quanto maior o poder (macht), maior a responsabilidade. Porém, não será renunciando ao poder que se isentará da responsabilidade, pois para conduzir os perigos e as ameaças frente à Natureza, é necessário estar atentos às condições políticas, aos sistemas democráticos e, principalmente, às catástrofes anunciadas. Conforme afirma Oliveira: "Tanto a promessa utópica da técnica como o seu potencial apocalíptico tem como consequência danosa o esvaziamento dos valores tradicionais, porque o novo cenário, justamente pela novidade de suas características e pela dimensão ampliada de seus riscos, não foi enfrentado por nenhum sistema ético do passado (2012, p.12). É diante desta projeção que considera-se fundamental uma perspectiva adicionada à dimensão da ética, pois esta, afirma Jonas, deverá sempre ser um ensino sobre como deveremos nos comportar na ação (aktion). 
Toda ação tem que ver com a realidade, uma parte importante dela é imposição, porque vivemos em um mundo que queremos algo e que, por sua parte, tem suas próprias leis, que não podem ser evitadas, sem mais, a vontade. Já faz um tempo que nos encontramos diante de um estado de realidade que nos impõe exigências e obrigações de atuar, mas que também nos oferece possibilidades que antes nem sequer existiam. Nesta situação é necessário repensar os deveres éticos. Isto não significa forçosamente que precisemos de uma nova ética, mas sim que existe um campo de aplicação radicalmente novo para a moral, para a exigência $e$ para o "deves" e não "deves". Uma nova situação como esta, é dizer, a era da alta tecnologia requer uma nova reflexão ética (2001, p.87-88).

A partir desta concepção, é eminente que a Responsabilidade passe a ser a primeira obrigação da reflexão ética, pois segundo Jonas, se as éticas anteriores não tiveram que considerar tais questões, é por que: "Nunca houve, nem qualitativamente nem quantitativamente, tanto do que se responsabilizar como agora" (2001, p.151). Todavia, a Responsabilidade, além de ser a primeira obrigação da reflexão ética, passa a assumir um papel importante na Educação, uma vez que a mesma nunca teve tanto do que se responsabilizar como agora, pois nunca existiu um cenário tão catastrófico $e$ alarmante, como nos últimos cem anos de história. Esquirol contribui afirmando que: "vivemos em um contexto essencialmente novo, determinado pela técnica, na qual requer uma nova ética capaz de estar à altura dos problemas relacionados com esse novo contexto" (2011, p.112).

É pensando nestas questões, que envolvem o futuro (Zukunft) da vida, que Jonas estabelece um imperativo ético capaz de superar a insuficiência dos modelos éticos antropocêntricos, ampliando a dimensão e a universalização (universalisierung) das ações coletivas.

Movido por este desejo, Jonas vislumbra um imperativo categórico compatível com as exigências da contemporaneidade e anuncia com as seguintes palavras: "Aja de modo que os efeitos da tua ação sejam compatíveis com a permanência de uma autêntica vida humana sobre a Terra" (2006, p.47) 7 . Ou seja, não coloque em perigo a conservação, a preservação, a integridade, nem a

\footnotetext{
${ }^{7} \mathrm{Na}$ tradução para o Espanhol "Obra de tal modo que los efectos de tu acción sean compatibles com La permanecia duna vida humana auténtica em La Tierra" (1994,p.40)
}

Número 25: nov/2015 - abr/2016 
essência da humanidade, pois a continuidade da vida depende de ações humanas responsáveis e coletivas sobre a Terra. É a partir deste princípio que Jonas passa a analisar a importância desta fundamentação para as gerações presentes $e$ vindouras, adentrando, assim, numa fundamentação ontológica que possa compreender a proficuidade que é pensar a vida na sua complexidade.

O princípio jonasiano apresenta, enquanto exigência moral, a superação do abismo existente entre o dualismo: Homem e Natureza, pois, até então, outras formas de vida nunca haviam sido contempladas ou adentradas na reflexão moral. Por exemplo, a Natureza sempre foi considerada um bem, mas não um bem em si, assim como o saber e o poder eram segundo Jonas, “(...) demasiados limitados para prever o futuro distante, $e$ incluso, incluir o globo terrestre na consciência da causalidade própria" (2001, p.151). Acreditando na capacidade e na potencialidade humana, Jonas passa a ampliar toda a esfera da Responsabilidade para o mundo da natureza, pois é dela que provém a garantia e a continuidade da vida no planeta. Na afirmação de Zancanaro, "Vida e natureza são, para Jonas, interdependentes e, dialeticamente, complementares" (2011, p.91).

Respectivamente, para que a humanidade continue existindo, é necessário que exista, além de homens, um meio ambiente equilibrado e conservado. Por meio deste pensamento, Jonas ressalta que o imperativo ontológico, surgido de forma ôntica, institui: “(...) a 'causa no mundo' fundamental ainda que não apenas a causa única, perante a qual a humanidade existente se torna desde então responsável" (2006, p.177).

Nas palavras de Giacóia, com as éticas tradicionais,

Os homens eram objeto do dever humano e, no mais extremo caso, a humanidade, e nada, além disso, sobre essa terra (costumeiramente, o horizonte ético era traçado de modo muito mais estreito, como no "ama o teu próximo"). Nada disso perde sua força vinculante. Porém, agora, a inteira biosfera do planeta, com toda sua pletora de espécies, em sua recém-revelada vulnerabilidade, perante os ataques excessivos do homem, exige sua parte de respeito, devido a tudo aquilo que traz em si mesmo o seu fim, isto é, todo vivente. O direito exclusivo do homem à humana consideração e à observância ética foi rompido precisamente com a conquista de um poder quase monopolístico sobre toda outra vida. Com um poder planetário de primeiro nível, não lhe é mais lícito pensar apenas em si mesmo. Em verdade, o mandamento de não legar a nossos descendentes uma herança desertificada expressa essa ampliação 
do campo ético de visão sempre, ainda, no sentido de um dever humano perante homens - como intensificação de uma solidariedade interhumana no sobreviver e no tirar proveito, na curiosidade, no desfrutar $e$ no admirar-se (1999, p.412).

Hoje, com infinitas possibilidades de informações e de conhecimentos, o ser humano passa a apresentar condições e capacidades para discernir que a natureza, assim como o homem, tem direitos, mas somente o ser humano tem a capacidade de exercer a Responsabilidade, pois segundo Jonas, ele:

(...) é o único ser conhecido que pode ter responsabilidade, por isso, justamente, a tem. Uma simples intuição nos diz que a presença de responsabilidade é melhor que sua absoluta falta. (...) Que no futuro siga havendo responsabilidade se converte, então, em um dever da responsabilidade. Isto só é possível se os seres que podem ser responsáveis sigam existindo (2001, p.72).

A partir desta concepção jonasiana, é ainda mais fortalecida a ideia de que a Responsabilidade deve estar permanentemente presente e vigente na essência do Ser, pois, segundo o autor, "(...) a perda do respeito pela subjetividade suporia, verdadeiramente, um grande perigo para a humanidade" (2001, p.79). Trata-se de um imperativo incondicional que possa garantir a existência de uma "vida humana autêntica", que tenha como tarefa levar a realização do "fim de todos os fins", ou seja, garantir o predomínio do Ser sobre o não Ser.

A vida passou a ter uma finalidade, subjetividade e um significado distintamente novo através da compreensão de Jonas, interpretado por Wollin com as seguintes palavras: (...) a vida tem que se manter tenazmente em ser; tem que empreender uma série de complexas e engenhosas ações de auto - conservação para não sucumbir à sua diabólica contrária, a morte. Deste modo, o drama da vida, suspenso momentaneamente entre o ser e não-ser a negação dá início à idéia da finalidade existencial (2003, p. 174-175).

Por meio desta compreensão, não poderá faltar, na teoria ética, a dimensão deontológica (essa que orienta as escolhas sobre o que deve ser feito), 
caso contrário, as obrigações do ser humano com a natureza não iriam persuadir. É preciso incluir o mundo físico no universo moral, pois não se pode separar o futuro da humanidade, do futuro da Natureza, caso contrário, se esse princípio não for respeitado, estar-se-á desumanizando o próprio ser humano ou, na visão de Jonas, "atrofiando sua essência" (1994, p.227).

Por fim, por meio deste artigo, busca-se apresentar aspectos relevantes da trajetória de vida e do percurso teórico de Hans Jonas, para poder compreender os motivos que levaram o autor a analisar sobre a condição, o desrespeito e o descaso com a vida diante do cenário alarmante da Técnica Moderna. Esses foram somente alguns dos motivos que fizeram Jonas analisar as inconsistências das éticas tradicionais para garantir um mundo viável aos seres que vivem $e$ aos seres que virão. Nesta ordem, a fundamentação de um princípio que busca, por meio da Responsabilidade, uma fundamentação ética para pensar a vida na sua totalidade, é vigente. No entanto, para que a Responsabilidade moral passe a integrar o âmbito da universalização dos valores, é preciso reconhecer, assim como Jonas, a necessidade de "repensar nossa responsabilidade" (2001, p.151). Repensar é pensar o antes pensado e repensar as próprias responsabilidade, é analisar as próprias escolhas, ações e condutas.

\section{Sobre o quê a Educação é responsável?}

Compreende-se que a responsabilidade e a Educação deveriam ser intrínsecas, uma vez que uma Educação sem comprometimento e sem responsabilidade não deveria ser efetivamente chamada de Educação. No olhar de Zancanaro, a educação, "só tem sentido se for intrinsecamente ética. Da mesma forma, a educação para a cidadania só terá sentido quando a ética for a sua condição" (2006, p.161).

Todavia, a incerteza e a inquietação ainda apontam para as seguintes questões: A responsabilidade se aprende? Se ensina? Para muitos educadores, tais questões estão relacionadas aos costumes de uma educação moral e religiosa $e$ essas, sem dúvida, são formas relevantes e importantes para pensar as práticas educacionais. No entanto, subentende-se que a responsabilidade não está 
relacionada a nenhum grupo social. Não está limitada a nenhum tipo de didática. Não pertence a nenhuma instituição de ensino. Não faz parte de nenhum tipo de gestão estratégica ou de um determinado grupo político. A responsabilidade é uma forma de vida, pois a partir do momento em que se assume uma causa e se vive por ela, estar-se-á universalizando a essência do bem.

Para compreender sobre o quê a Educação é responsável, é preciso decidir o que pode ou não ser viável e necessário para a Educação juntamente com a opinião pública. Por exemplo, a Lei de Diretrizes e Bases da Educação Nacional (LDB) apresenta no capítulo VI, da lei n. 9.394/1996, a afirmação de que a educação deve estimular o conhecimento dos problemas do mundo presente, em particular os problemas nacionais e regionais, além de prestar serviços especializados à comunidade e estabelecer com esta uma relação de reciprocidade.

Por mais que as instituições educativas constituam e estabeleçam valores $e$ atitudes na vida dos seres humanos, compreende-se que o ato de educar, enquanto tarefa de toda a sociedade, é um assunto recente. A Educação, conforme Zancanaro, "(...) é exatamente o reflexo dessas políticas públicas em prol do coletivo" (2006, p.168). Ao encontro desta ideia, o artigo $1^{\circ}$, da lei n. 9.394/1996, da LDB, afirma que a educação abrange os processos formativos que se desenvolvem na vida familiar, na convivência humana, no trabalho, nas instituições de ensino, nas pesquisas, nos movimentos sociais, nas manifestações culturais e na organização da sociedade civil. Ou seja, a educação é capaz de envolver todas as esferas das sociedades, na medida em que o ser humano se sinta parte integrante deste "projeto comum" $e$, para isso, ele deverá ser atuante e participativo. Ou, nas palavras de Jonas, ele deverá assumir a sua totalidade para garantir a continuidade. Ao encontro desta ideia, Gadotti afirma que uma sociedade participativa, além de apelar para a responsabilidade e participação de todos, exige o diálogo e a crítica, que "(...) permite ao homem se colocar enquanto sujeito, como membro de um grupo, como participante de um projeto comum" (1981, p.156).

No entanto, estaria a Educação preparada para assumir uma responsabilidade e viver por sua causa? É importante salientar que a Educação 
está diante de novos desafios, valores, comportamentos e, principalmente, de novos objetos de reflexão. A maioria deles é proveniente dos avanços da ciência e da tecnologia que, por sua vez, geram novos processos civilizatórios e produzem novos objetos de reflexão. Neste âmago, os educadores deverão, com urgência e prioridade, voltar sua atenção para este novo cenário, de novos desafios e de diferentes reflexões, bem como assumir toda $e$ qualquer causa com responsabilidade. O educador Georgen contribui afirmando que: "A sociedade em seus diferentes ambientes, é responsável pela formação ética das futuras gerações" (2001, p.83).

Por esta via, compreende-se que, a partir do momento em que o educador assumir suas ações e condutas com responsabilidade, poderá assumir outras formas de responsabilidade com a sociedade e, sobretudo, com a vida. Por outro lado, Zancanaro afirma que o educador tem a responsabilidade de pensar ações condizentes com a seguinte realidade: "Que tipo de humanidade e de sociedade são desejadas? A partir de que valores? Quais ações imediatas deverão ser operadas para viabilizar o que é desejado?" (2006, p.161-162).

A proposta jonasiana não diz exatamente como se deve atuar em situações concretas com a educação em nível formal. Mas, em contrapartida, deixa possibilidades para pensar tanto em nível de reflexão filosófica, quanto em nível prático e transversal dos diferentes campos do conhecimento. Neste sentido, Jonas deixa clara a importância de que poder “(...) despertar, manter, incluso fundamentar um sentimento de 'humanidade' é uma importantíssima tarefa educativa e intelectual para o mundo de amanhã" (1997, p.52).

Através desta importante "tarefa educativa" é possível, assim como propõe Jonas, fundamentar uma responsabilidade ancorada no sentimento para o mundo de amanhã. Por exemplo, por meio de uma ética fundamentada em bons valores e em bons princípios, será possível estabelecer fundamentos epistemológicos e pedagógicos plausíveis de serem avaliados na atual conjuntura educacional. Somente assim será possível conhecer, analisar e avaliar toda e qualquer ação. Ou 
seja, é preciso o "conhecimento do conhecimento" pensando o futuro da humanidade, questiona-se se o conhecimento sempre será insuficiente em relação a um prognóstico? Para analisar essa questão, Jonas afirma que reconhecer a própria ignorância "torna-se, então, o outro lado da obrigação do saber e, com isso, torna-se uma parte da ética que deve instruir o autocontrole, cada vez mais necessário, sobre o nosso excessivo poder" (2006, p.41).

Observar o que vai além do reconhecimento das capacidades $e$ incapacidades originárias das obrigações do saber e do poder deveriam ser obrigações e tarefas da educação, pois a amplitude do horizonte teórico, por exemplo, pode oferecer, além de um método de ensino e de investigação, um sistema educativo que esteja compatível com as necessidades vigentes de cada sociedade, pois em cada sociedade, em cada nação, há uma ampla diversidade cultural, mas em nenhuma circunstância, é possível isentar o comprometimento, o respeito, o cuidado e a responsabilidade pela vida.

\section{REFERÊNCIAS}

ABBAGNANO, Nicola. Dicionário de Filosofia. São Paulo: Martins Fontes, 2007.

BRUSEKE, Franz Josef. A modernidade Técnica. Revista Brasileira de Ciências Sociais. Vol.17. No.49, 2002.

DUPLÁ, Leonardo Rodriguez. Uma ética para La civilización tecnológica de Hans Jonas. In: GÓMEZ Heras, José. Ética del medio ambiente. Problema, perspectivas, historia. Madrid: Tecnos, 1997.

ESQUIROL, M, Josep. Los Filósofos contemporáneos y la técnica de Ortega a Sloterdijr. Barcelona: Gedisa, 2011.

ETCHEGOYEN, Alain. La vrai Morale se Moque de la Moral. Être Responsable. Paris: Seuil,1999.

GADOTTI, Moacir. A educação contra a educação. Rio de Janeiro: Paz e Terra, 1981.

GEORGEN, Pedro. Pós-modernidade, ética e educação - polêmicas do nosso tempo. Campinas: Autores associados, 2001.

\footnotetext{
8 O termo "conhecimento sobre o conhecimento" foi abordado por Edgar Morin, na sua obra sobre O método 3, neste o autor menciona sobre questões básicas da epistemologia, apresentando uma antropologia do conhecimento. Nas palavras do autor, "o conhecimento do conhecimento requer um pensamento complexo, que requer necessariamente o conhecimento do conhecimento (...) ou seja, um pensamento ao mesmo tempo dialógico, reflexivo e hologramático" (1999,p. 256, 257)
} 
GERNARD, Jean- Louis. La Grammaire de la Responsabilité. Paris: Éditions Du Cerf,1999.

GIACOIA Junior, Oswaldo. Hans Jonas: por que a técnica moderna é um objeto para a ética. Natureza humana, vol.1, No. 2, Dez 1999, p.407-420.

JONAS, Hans. O Princípio Responsabilidade: Ensaio de uma ética para uma civilização tecnológica. Rio de Janeiro: PUC Rio, 2006.

. Más cerca del Perverso Fin y outros Diálogos y Ensayos. Tradución de Illana Giner Comín. Madrid: Catarata, 2001.

.El Principio de Responsabilidad: ensayo de una ética para la civilización tecnológica. Barcelona: Herder, 1994.

KUIAVA, Evaldo Antonio. A responsabilidade como Princípio ético em H. Jonas e E. Levinas: Uma aproximação. Revistas Veritas. Vol.51,2006.

MEISTER, José Antonio Fracalossi. O conceito vida como fundamentação ontológica da ética da Responsabilidade em Hans Jonas. 197f. Tese (Doutorado em Filosofia) Pontífica Universidade Católica do Rio Grande do Sul, Porto Alegre,2008.

MORIN, Edgar. O método 3: o conhecimento do conhecimento. Porto Alegre: Sulina, 1999.

OLIVEIRA, Jelson Roberto de. Da magnitude e ambivalência à necessária humanização da tecnociência segundo Hans Jonas. Cadernos IHU Ideias, São Leopoldo, No 176, p.01-27, 2012.

RICOEUR, Paul. Soi-Même Comme um Autre. Paris, 1990.

Paulo: Martins fontes, 2008.

WOLIN,Richard. Los Hijos de Heidegger: Hannah Arendt, Karl Löwith, Hans Jonas y Herbert Marcuse.Traducción de María Condor. Madrid: Huertas, 2003.

ZANCANARO, Lourenço. Ética para a civilização tecnológica: em diálogo com Hans Jonas. São Paulo: Centro Universitário São Camilo, p.250-266, 2011. 